\title{
Benefits of synchronizing ovulation with porcine luteinizing hormone (pLH) in a fixed time insemination protocol in weaned multiparous sows
}

\author{
L.J. Zak', J. Patterson', J. Hancock ${ }^{3}$, D. Rogan' and G.R. Foxcroft ${ }^{2}$ \\ 'Bioniche Animal Health, P.O. Box 1570, Belleville, ON, K8N 5/2, Canada; ${ }^{2}$ Swine Reproduction- \\ Development Program, Swine Research \& Technology Centre, University of Alberta, Edmonton, AB, \\ T6C 2P5. Canada; ${ }^{3}$ Picton Animal Hospital, 19 McSteven Drive, Picton, KOK 2TO, Canada
}

Insemination protocols are usually based on the onset of estrus, with a view to inseminating within a 24 hour window before or up to 16 hours after ovulation (Kemp \& Soede 1996). However, use of transrectal ultrasonography has shown that the time of ovulation relative to onset of estrus is highly variable, and dependent on weaning-to-estrus interval (WEI), duration of estrus and frequency of estrus detection (Weitze et al. 1994). Variation in the timing of the pre-ovulatory LH surge relative to onset of estrus is assumed to cause these differences in the time of ovulation during estrus (Tilton et al. 1982) and injection of porcine luteinizing hormone $(\mathrm{pLH})$ induces ovulation approximately $38 \mathrm{~h}$ after administration (Cassar et al. 2005). Using pLH at the onset of estrus, timed insemination 24 or more hours after pLH then ensures optimal fertility outcomes. The efficacy of combining pLH administration at first detection of standing heat in weaned multiparous sows in a commercial operation, followed with fixedtime double insemination, was initially compared to results from sows conventionally managed and inseminated multiple times until no longer in estrus.

Sows (parity 2-9) were assigned to treatment at weaning on d 21 of lactation. From the day of weaning, twice-daily boar exposure at $8 \mathrm{am}$ and $2 \mathrm{pm}$ facilitated estrus detection. Onset of behavioural estrus was defined as the time that sows first showed a standing response to back pressure in the presence of a boar. In accordance with normal farm practice, untreated control sows (CON; $n=156$ ) were inseminated at 6-, 18- and 24-h intervals based on their WEI and the time (am or pm) they were first recorded in estrus (See Table 1). After the second insemination, additional inseminations were employed at 24-h intervals until sows were no longer in standing heat. Sows assigned to LUT $(n=163)$ were administered $5 \mathrm{mg}$ pLH (Lutropin-V, Bioniche Animal Health, Belleville, ON; I.M. in $4 \mathrm{ml}$ of vehicle) concomitant with the first detection of standing heat. If sows were first detected in estrus in the morning $(8 \mathrm{am})$ they were inseminated at $8 \mathrm{am}$ and $2 \mathrm{pm}$ the next day ( 24 and $30 \mathrm{~h}$ after pLH injection). If estrus was first detected in the afternoon $(2 \mathrm{pm})$, sows were inseminated at $2 \mathrm{pm}$ the next day and $8 \mathrm{am}$ the following day ( 24 and $42 \mathrm{~h}$ after injection; see Table 2). Extended semen was $<3$ days old and contained a minimum of $3 \times 10^{9}$ live spermatozoa per dose. Data from sows that had a weaning to last insemination interval (WLII) $<2$ or $>10 \mathrm{~d}$ were removed from the analysis. Parities 7,8 and 9 were analyzed as one group (Parity $7+$ ). The effect of treatment, parity, and their interaction on number of inseminations, age of semen, WLII, litter size and weight born, and individual piglet weight were analyzed using a linear mixed effect model, with lactation length as a covariate. Proportions of sows bred that were pregnant and farrowed were analyzed using a chi-squared test.

There were significant effects of treatment and parity but no treatment by parity interaction for any variable measured. For the purposes of this presentation only the main effects of treatment 
are reported. The last insemination occurred sooner after weaning $(5.3 \pm 0.07$ vs. $5.8 \pm$ $0.08 \mathrm{~d} ; \mathrm{P}<0.001)$, the number of inseminations was fewer $(2.0 \pm 0.02$ vs. $2.2 \pm 0.02 ; \mathrm{P}<$ $0.001)$ and farrowing rate tended to be higher $(87.4 \mathrm{vs} .82 .3 \% ; P=0.1)$ in LUT compared to CON sows, respectively. Total pigs born and born alive was also greater $(P<0.01)$ in LUT $(12.9 \pm 0.3$ and $11.7 \pm 0.3$, respectively) compared to CON $(11.8 \pm 0.3$ and $10.6 \pm 0.3$, respectively) sows. Treatment had no affect on average piglet weight or on piglet removal rate due to low viability before cross fostering at $\mathrm{d} 3$ after farrowing.

Table 1. Untreated control sow insemination schedule

\begin{tabular}{|c|c|c|c|}
\hline WEI (d) & Estrus onset & $\begin{array}{l}1^{\text {st }} \text { insemination time / } \\
\text { Estrus to Al interval (h) }\end{array}$ & $\begin{array}{l}2^{\text {nd }} \text { insemination* } / \\
\text { Estrus to Al interval (h) }\end{array}$ \\
\hline \multirow[t]{2}{*}{$\leq 4$ days } & $\mathrm{am}$ & Same day pm $(6 \mathrm{~h})$ & Next day am (24 h) \\
\hline & pm & Next day am (18 h) & Following day am (42 h) \\
\hline \multirow[t]{2}{*}{$>4$ days } & $\mathrm{am}$ & Same day am $(0 \mathrm{~h})$ & Next day am (24 h) \\
\hline & pm & Same day pm $(0 \mathrm{~h})$ & Next day am (18 h) \\
\hline
\end{tabular}

* then inseminated at $24-\mathrm{h}$ intervals until no longer in standing estrus

Table 2. Lutropin treated sow insemination schedule

\begin{tabular}{lll}
\hline $\begin{array}{l}\text { Estrus onset / pLH } \\
\text { administration }\end{array}$ & $\begin{array}{l}1^{\text {st }} \text { insemination time / } \\
\mathrm{pLH} \text { to } \mathrm{Al} \text { interval }(\mathrm{h})\end{array}$ & $\begin{array}{l}2^{\text {nd insemination time } /} \\
\mathrm{pLH} \text { to Al interval (h) }\end{array}$ \\
\hline am & Next day am $(24 \mathrm{~h})$ & Next day pm (30 h) \\
$\mathrm{pm}$ & Next day pm (24 h) & Following day am (42 h) \\
\hline
\end{tabular}

These results indicate that administration of $\mathrm{pLH}$ at onset of behavioural estrus to control time of ovulation enables a double fixed-time insemination protocol to be employed, which resulted in reduced semen usage and labour devoted to estrus detection, and improved sow productivity. These data also provide preliminary information suggesting that administration of $\mathrm{pLH}$ concomitant with onset of estrus could be used to facilitate a fixed-time insemination protocol in which a single insemination is performed 24 or 30 hours after $\mathrm{pLH}$ administration.

\section{References}

Cassar G, Kirkwood RN, Poljak Z, Bennett-Steward K \& Friendship RM 2005 Effect of single or double insemination on fertility of sows bred at an induced estrus and ovulation. Journal of Swine Health and Production 13 254-258.

Kemp B \& Soede NM 1996 Relationship of weaning to estrus interval to timing of ovulation and fertilization in sows Journal of Animal Science 74 944-949.
Tilton JE, Foxcroft GR, Ziecik AJ, Coombs SL \& Williams GL 1982Time of the preovulatory LH surge in the gilt and sow relative to the onset of behavioural estrus Theriogenology 18 277-236.

Weitze KF, Wagner-Rietschel H, Waberski D, Richter L \& Krieter J 1994 The onset of heat after weaning, heat duration and ovulation as major factors in $\mathrm{Al}$ timing in sows Reproduction in Domestic Animals $29433-443$. 